\title{
Process Development Overcomes a Challenging Pd-Catalyzed C-N Coupling for the Synthesis of RORc Inhibitor GDC-0022
}

Lauren E. Sirois, * ${ }^{+}$David Lao, Jie Xu, Rémy Angelaud, Jerry Tso, Brandon Scott,, Paroma Chakravarty, "Sushant Malhotra,' and Francis Gosselin

Department of Small Molecule Process Chemistry, sDepartment of Small Molecule Analytical Chemistry, "Department of Small Molecule Pharmaceutics, and Department of Small Molecule Discovery Chemistry, Genentech, Inc., 1 DNA Way, South San Francisco, California 94080, United States; Present address: Tricida, Inc., 7000 Shoreline Court, Suite 201, South San Francisco, CA 94080, United States.

\section{Table of Contents}

Figure S1 NMR Spectra for Compound 8

Figure S2 NMR Spectra for Compound 3

$\begin{array}{lll}\text { Figure S3 NMR Spectra for Compound } 9 & \text { S6 }\end{array}$

$\begin{array}{lll}\text { Figure S4 NMR Spectra for Compound } \mathbf{1 1} & \text { S7 }\end{array}$

$\begin{array}{lll}\text { Figure S5 NMR Spectra for Compound } 12 & \text { S8 }\end{array}$

$\begin{array}{lll}\text { Figure S6 NMR Spectra for Compound } 4 & \text { S9 }\end{array}$

$\begin{array}{lll}\text { Figure S7 NMR Spectra for Compound 2 } & \text { S10 }\end{array}$

$\begin{array}{lll}\text { Figure S8 NMR Spectra for GDC-0022•pTsOH } & \text { S12 }\end{array}$

Figure S9 $\quad$ Effects of KBr and Additional XantPhos on C-N Coupling $\quad$ S14 
Figure S1. 'H NMR (400 MHz, $\left.\mathrm{CDCl}_{3}\right),{ }^{\mathrm{i}} \mathrm{C}\left\{{ }^{\prime} \mathrm{H}\right\} \mathrm{NMR}\left(101 \mathrm{MHz}, \mathrm{CDCl}_{3}\right)$, and ${ }^{\circ} \mathrm{F}\{\mathrm{H}\} \mathrm{NMR}\left(376 \mathrm{MHz}, \mathrm{CDCl}_{3}\right)$ spectra for compound $\mathbf{8}$.
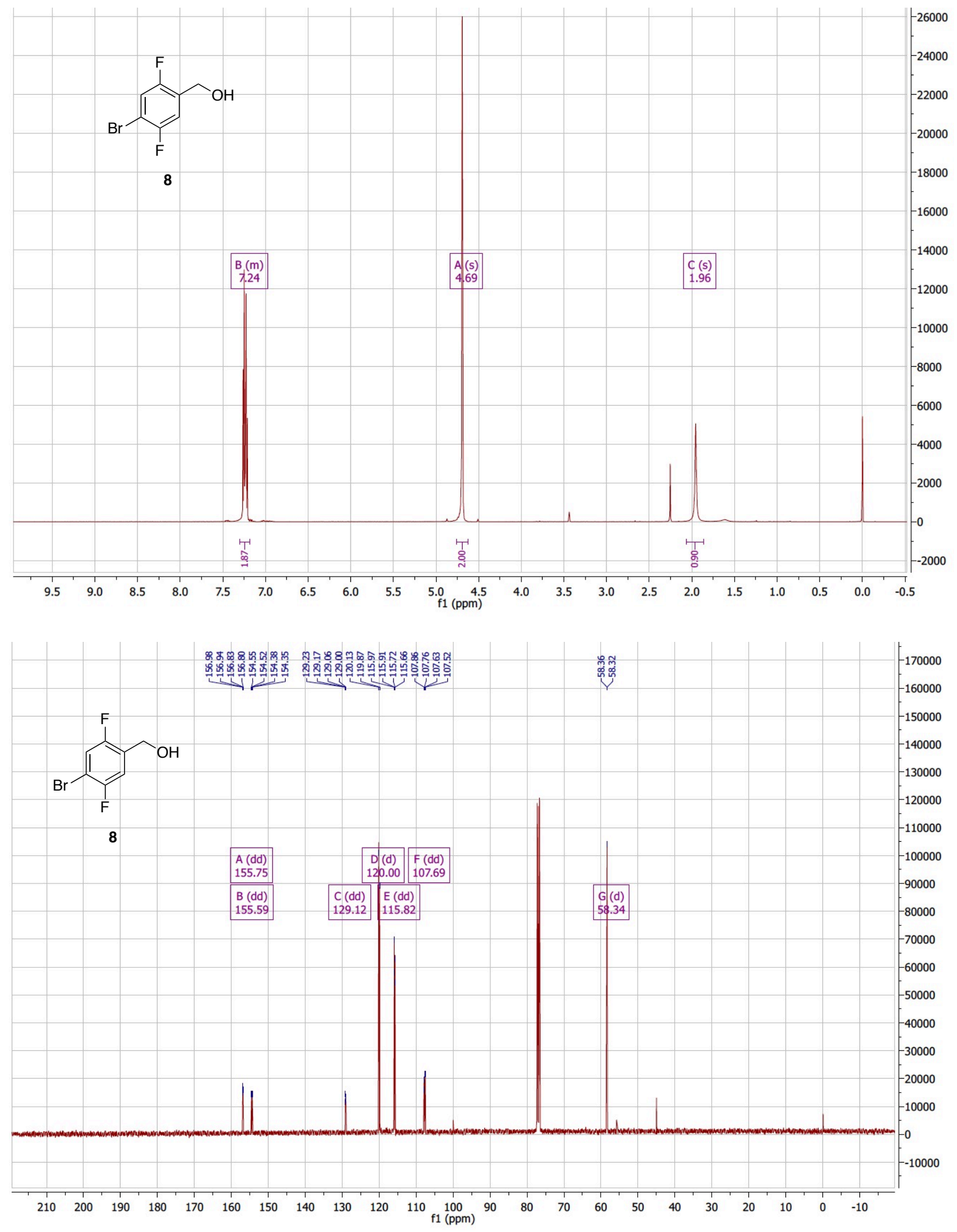


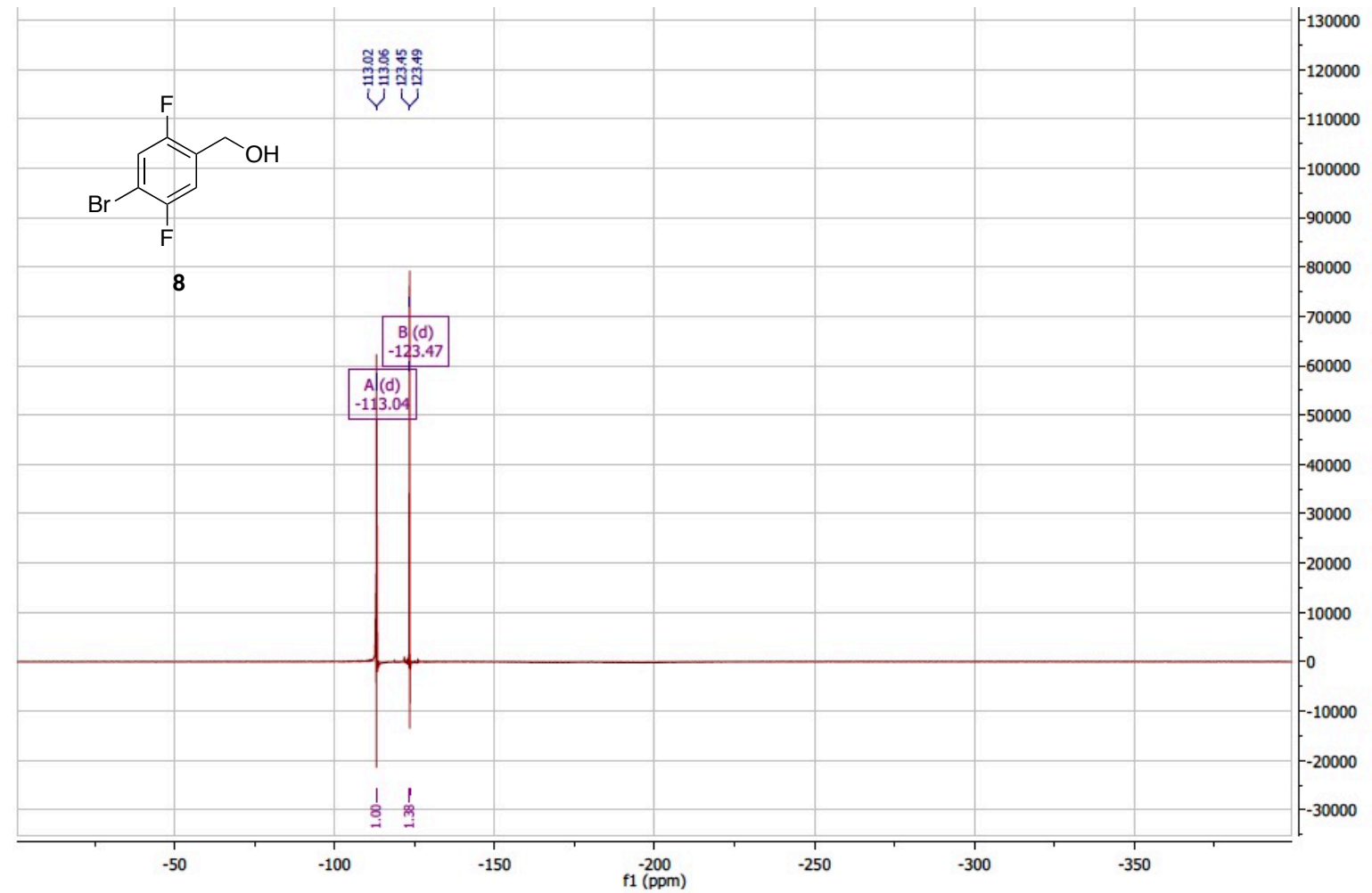


Figure S2. 'H NMR (500 MHz, chloroform-d), $\mathrm{C}\left\{{ }^{\prime} \mathrm{H}\right\}$ NMR (126 MHz, chloroform-d), ${ }^{\circ} \mathrm{F}\left\{{ }^{\prime} \mathrm{H}\right\} \mathrm{NMR}(376 \mathrm{MHz}$, DMSO- $d_{6}$ ) spectra for compound $\mathbf{3}$.
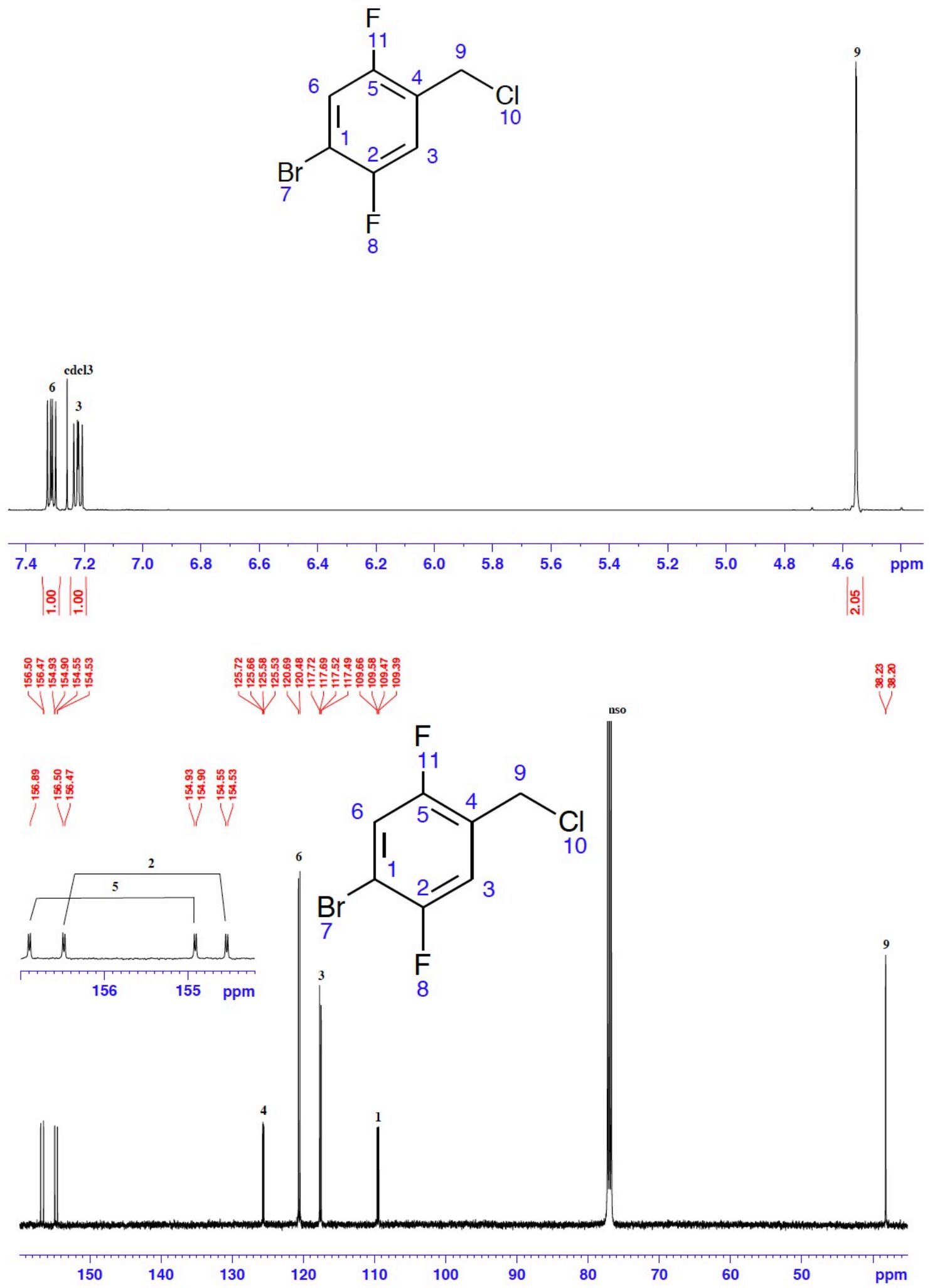


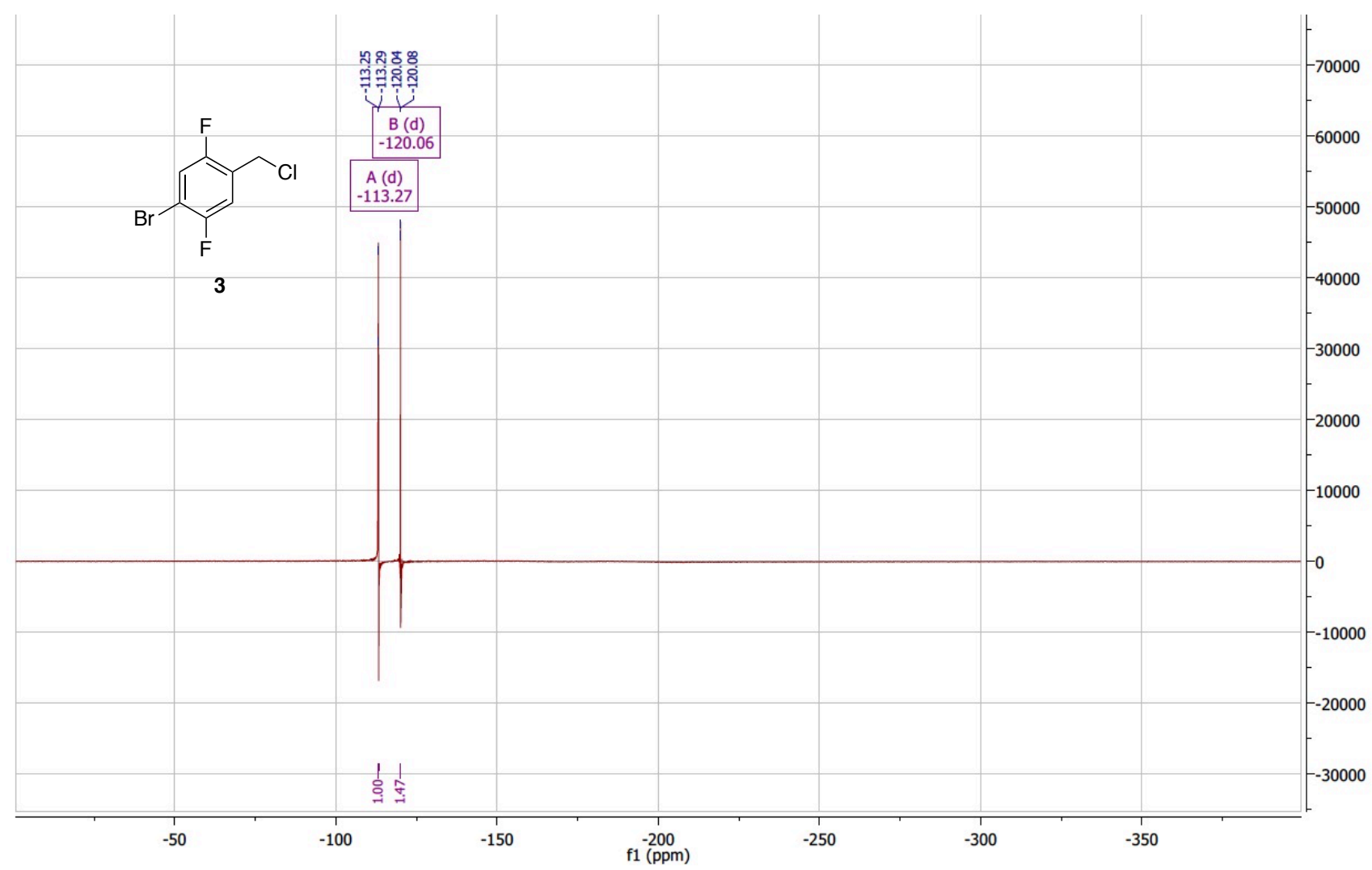


Figure S3. 'H NMR (400 MHz, DMSO- $\left.d_{6}\right)$ and $\mathrm{C}\left\{{ }^{\prime} \mathrm{H}\right\}$ NMR (101 MHz, DMSO- $\left.d_{6}\right)$ spectra for compound 9.
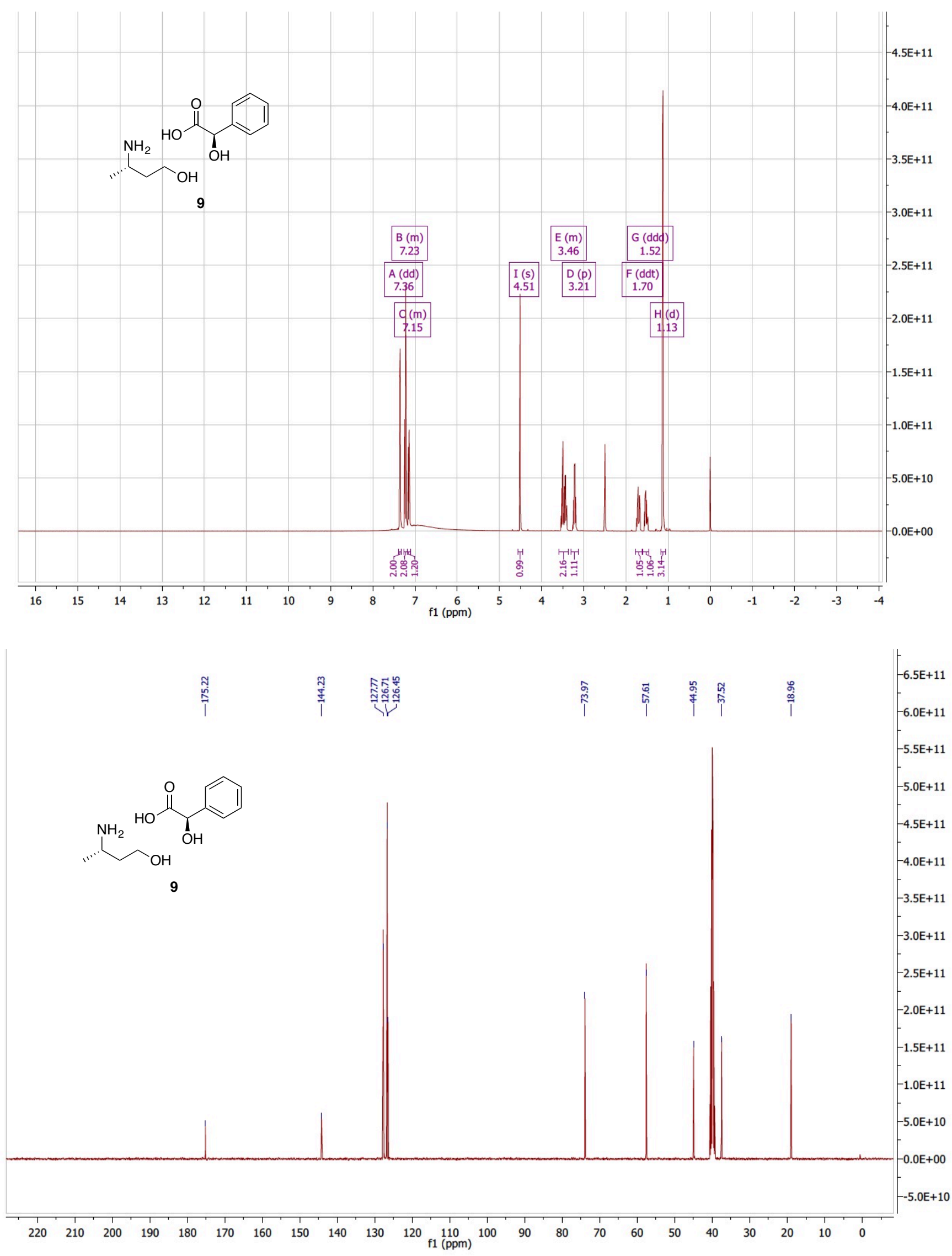
Figure S4. 'H NMR (400 MHz, DMSO- $\left.d_{6}\right)$ and $\mathrm{C}\left\{{ }^{\prime} \mathrm{H}\right\}$ NMR (101 MHz, DMSO- $\left.d_{6}\right)$ spectra for compound 11.
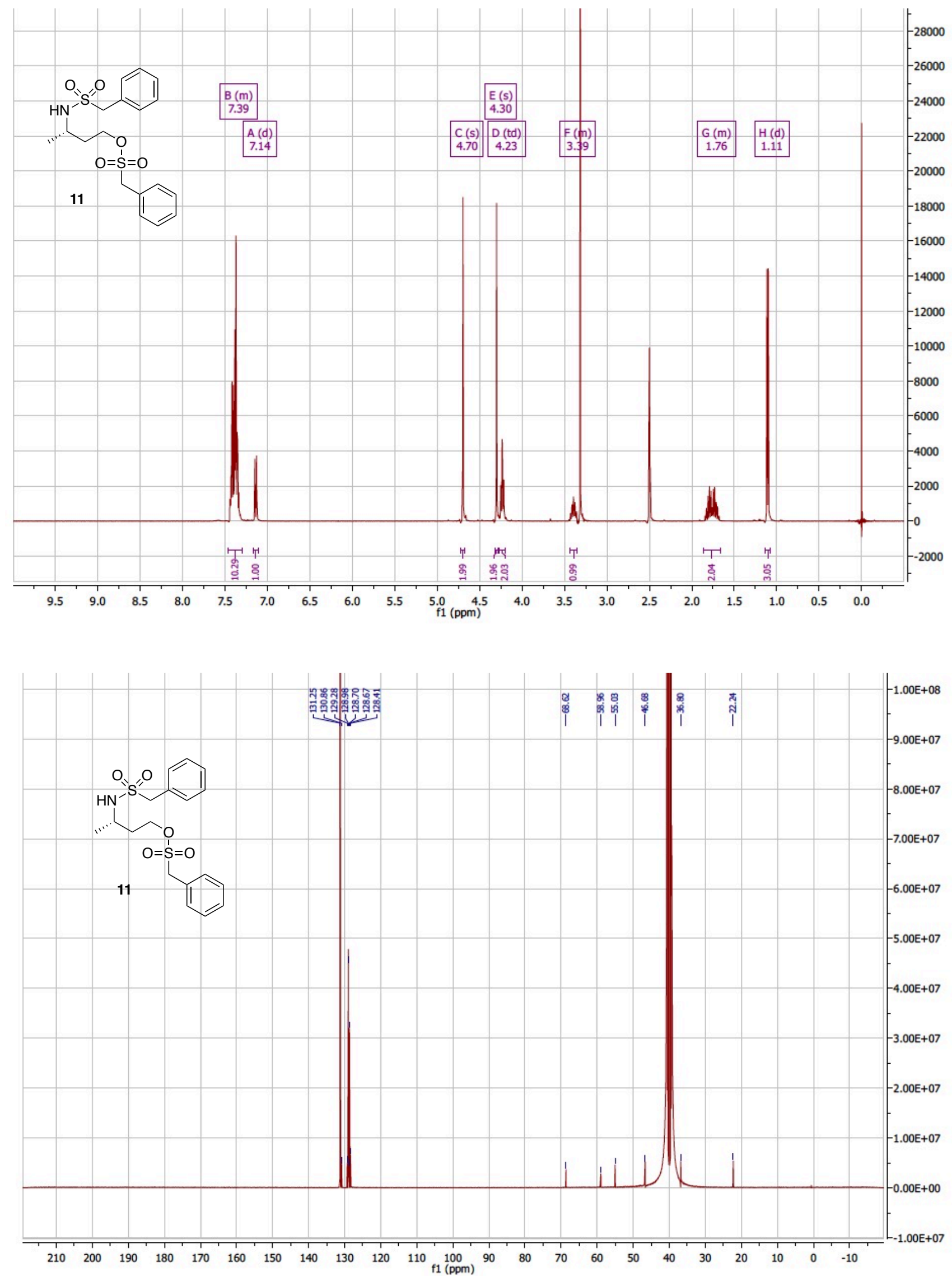
Figure S5. 'H NMR (400 MHz, DMSO- $\left.d_{6}\right)$ and ${ }^{\mathrm{C}} \mathrm{C}\left\{{ }^{\prime} \mathrm{H}\right\}$ NMR $\left(101 \mathrm{MHz}, \mathrm{DMSO}-d_{6}\right)$ spectra for compound 12.
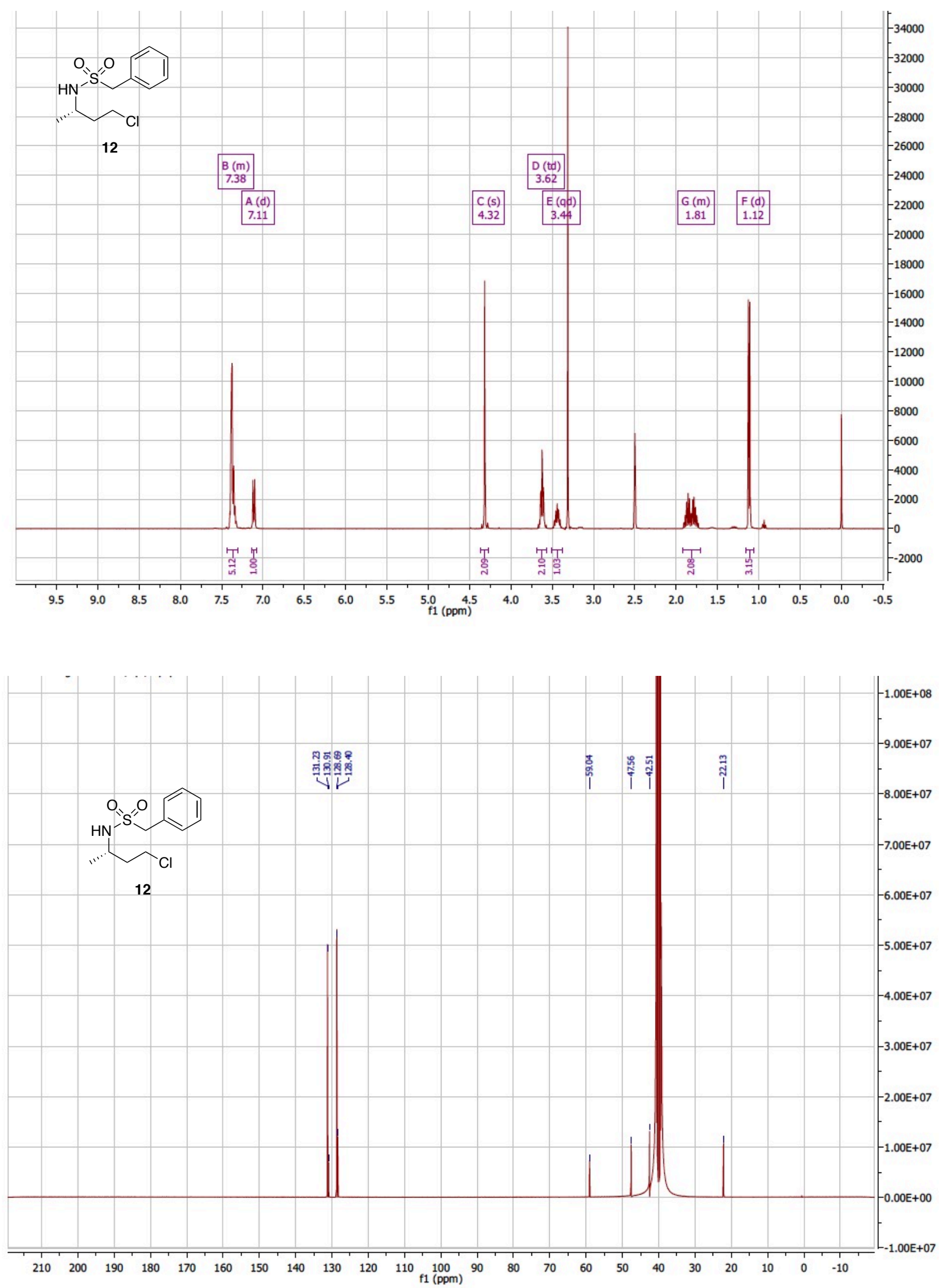
Figure S6. 'H NMR (500 MHz, DMSO- $\left.d_{6}\right)$ and ${ }^{:} \mathrm{C}\{\mathrm{H}\}$ NMR (101 MHz, DMSO- $\left.d_{6}\right)$ spectra for compound 4.
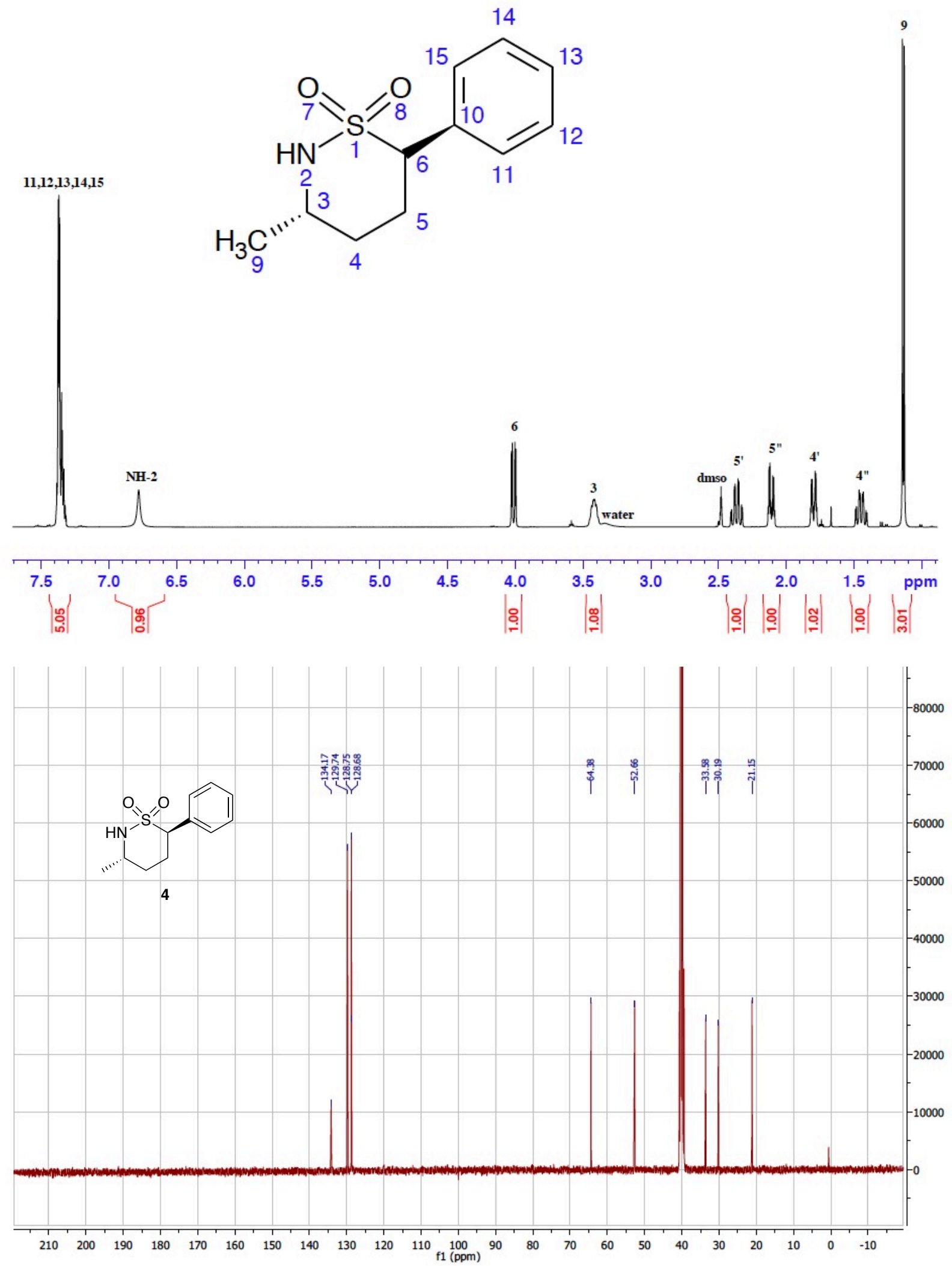
Figure S7. 'H NMR (500 MHz, DMSO- $\left.d_{6}\right)$, ${ }^{\mathrm{C}} \mathrm{C}\left\{{ }^{\prime} \mathrm{H}\right\}$ NMR (126 MHz, DMSO- $\left.d_{6}\right)$, and ${ }^{\circ} \mathrm{F}\left\{{ }^{\prime} \mathrm{H}\right\}$ NMR (376 MHz, DMSO$d_{6}$ ) spectra for compound 2 .
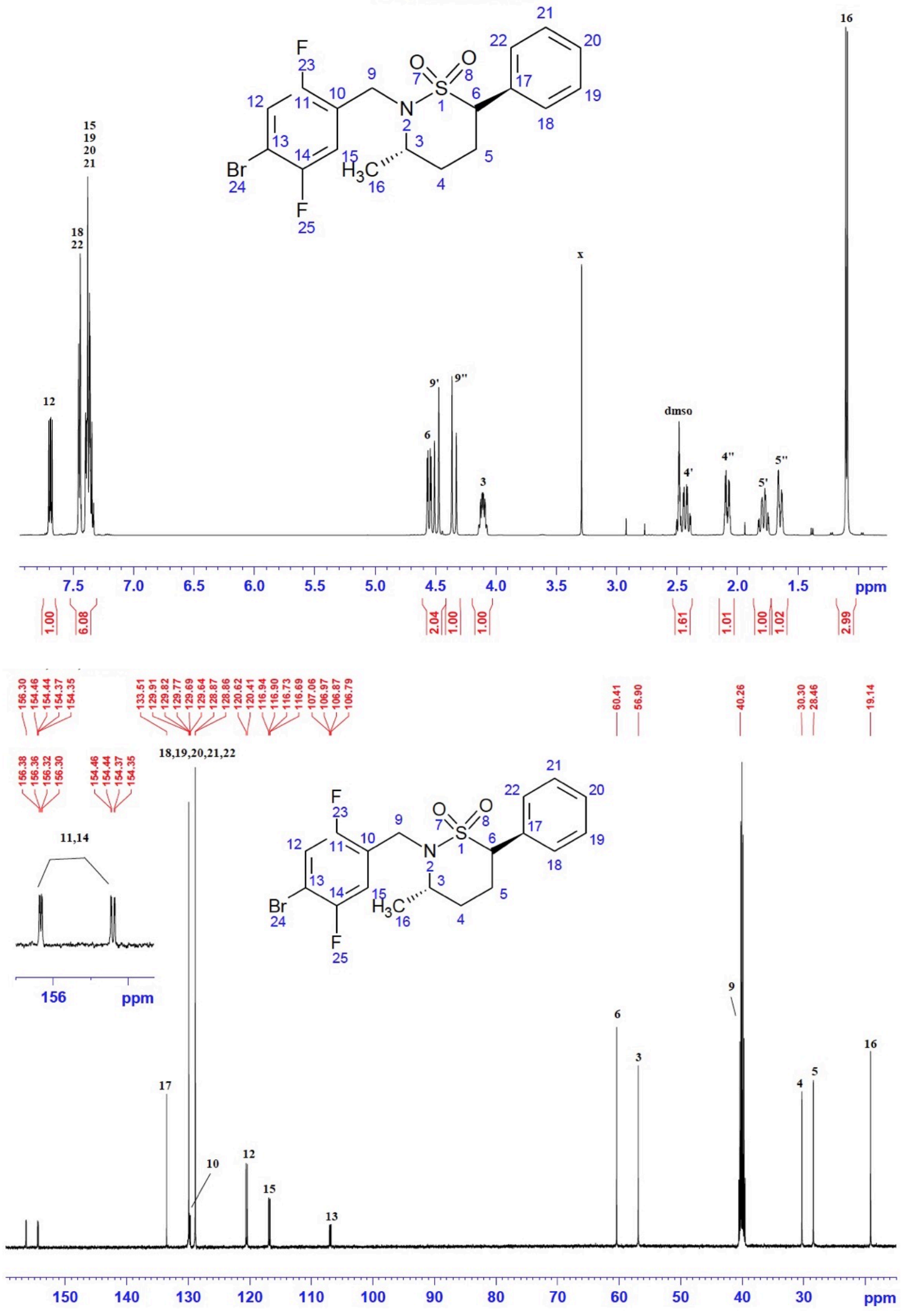


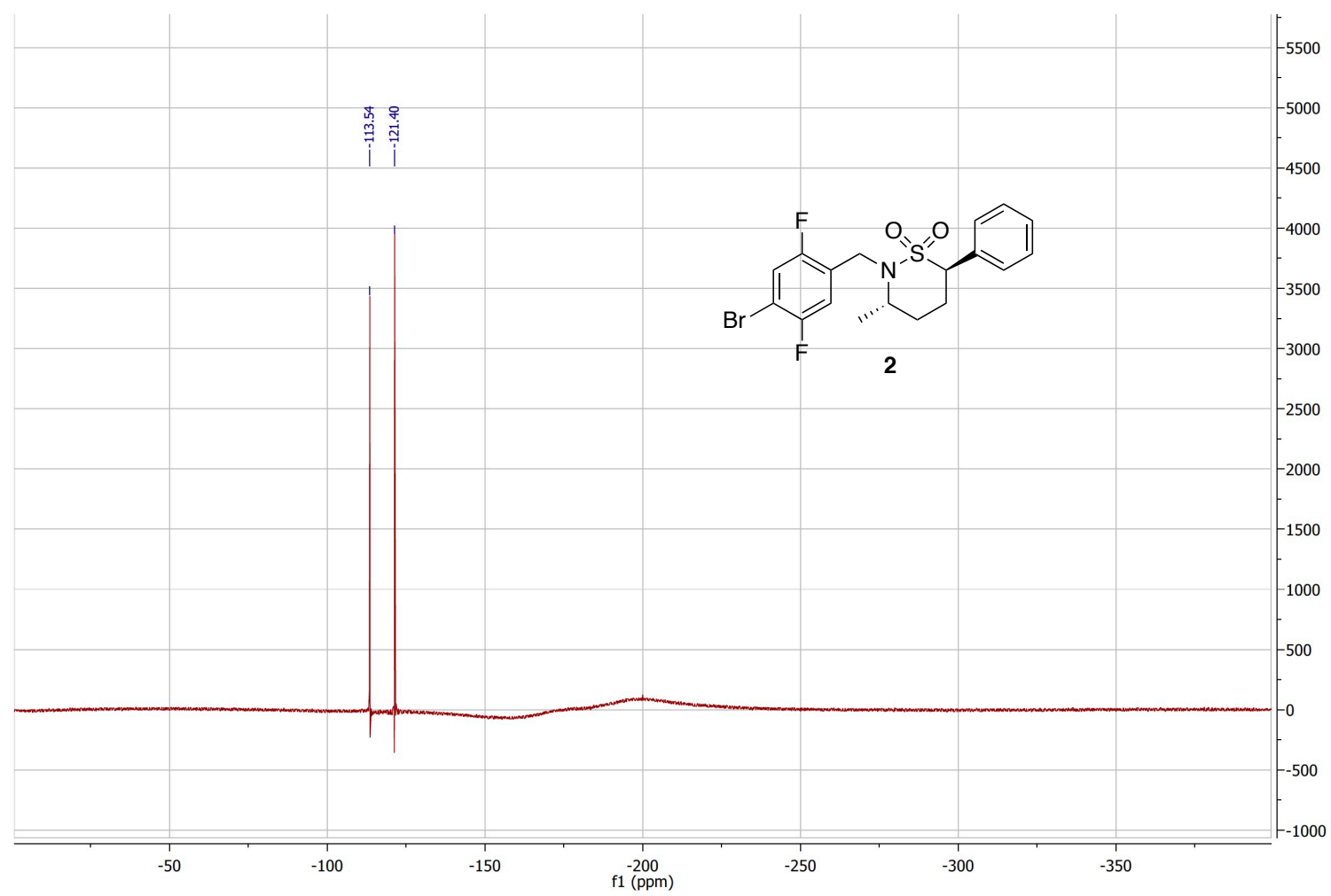


Figure S8. 'H NMR (500 MHz, DMSO- $\left.d_{6}\right)$, ${ }^{\mathrm{B}} \mathrm{C}\left\{{ }^{\prime} \mathrm{H}\right\}$ NMR (101 MHz, DMSO- $\left.d_{6}\right)$, and ${ }^{\circ} \mathrm{F}\left\{{ }^{\prime} \mathrm{H}\right\}$ NMR (376 MHz, DMSO$d_{6}$ ) spectra for compound GDC-0022•pTsOH.
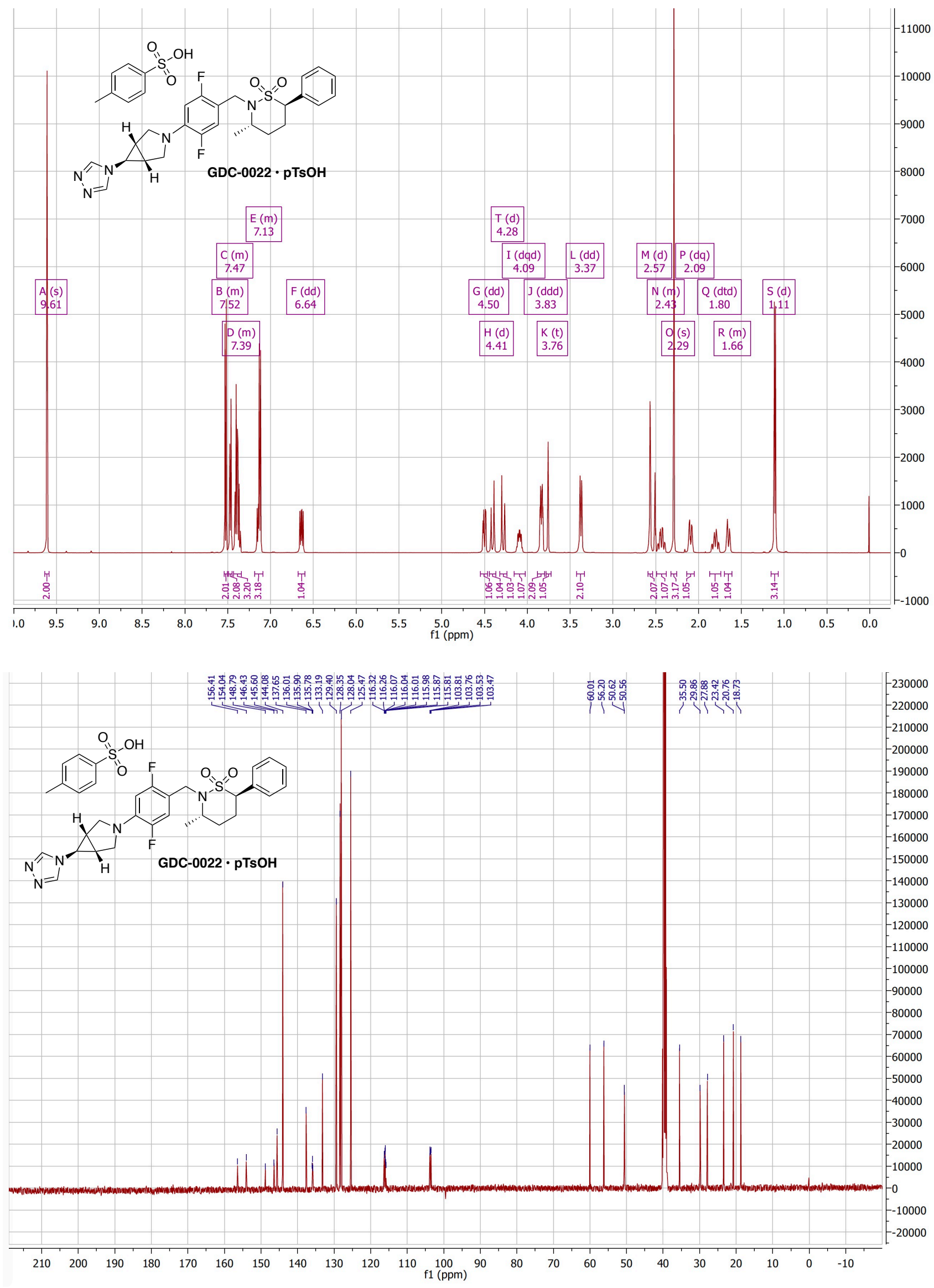


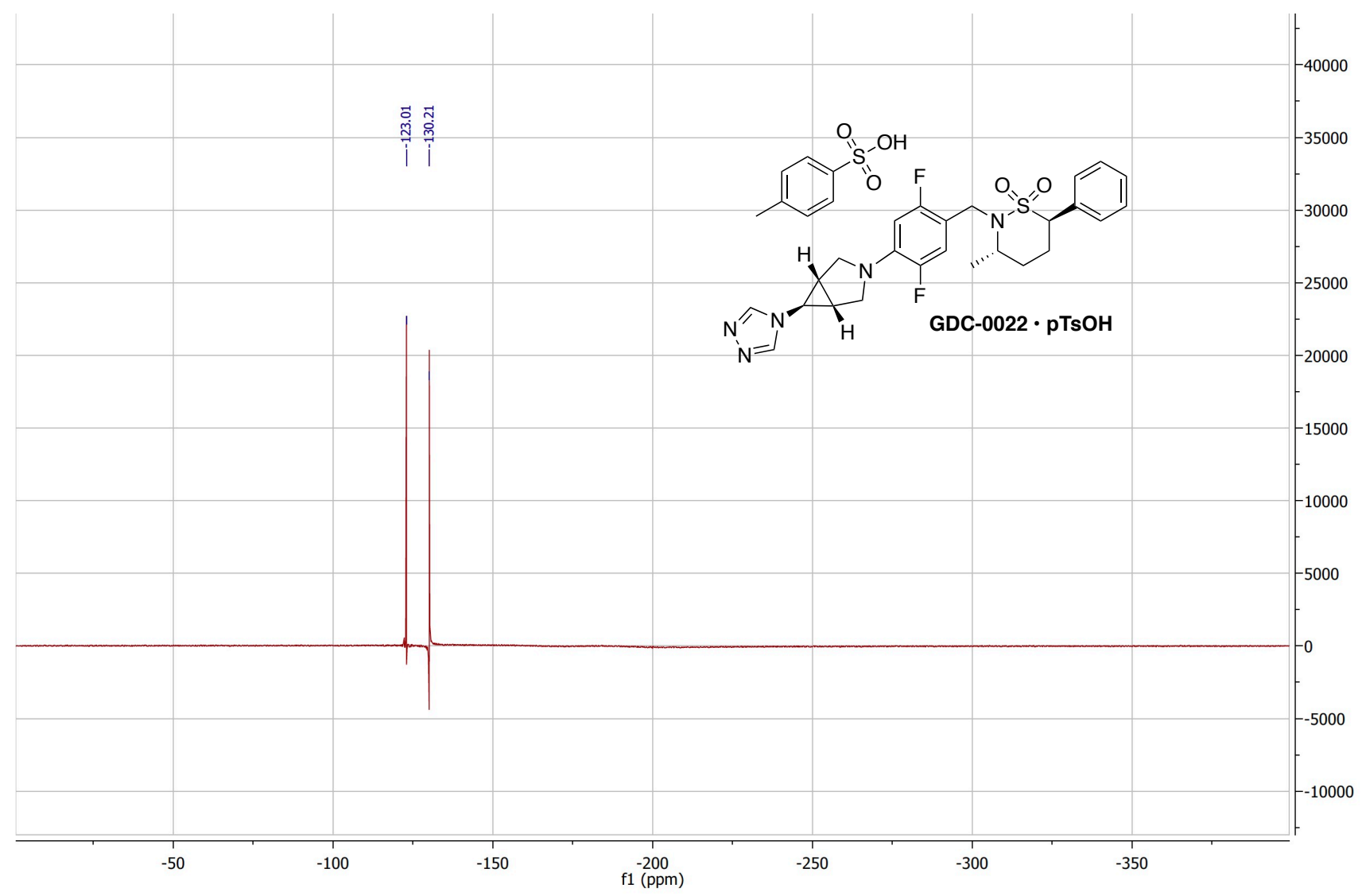


Figure S9. Effects of exogenous XantPhos and $\mathrm{KBr}$ in the $\mathrm{C}-\mathrm{N}$ coupling of $\mathbf{2}$ and 1. Conditions: 2 (1.0 equiv), 1 (1.2 equiv), XantPhos-Pd-G2 (1 mol\%), $\mathrm{K}_{3} \mathrm{PO}_{4}\left(1.5\right.$ equiv), 1,4 -dioxane $(5 \mathrm{~mL} / \mathrm{g}), 95-100{ }^{\circ} \mathrm{C}$.
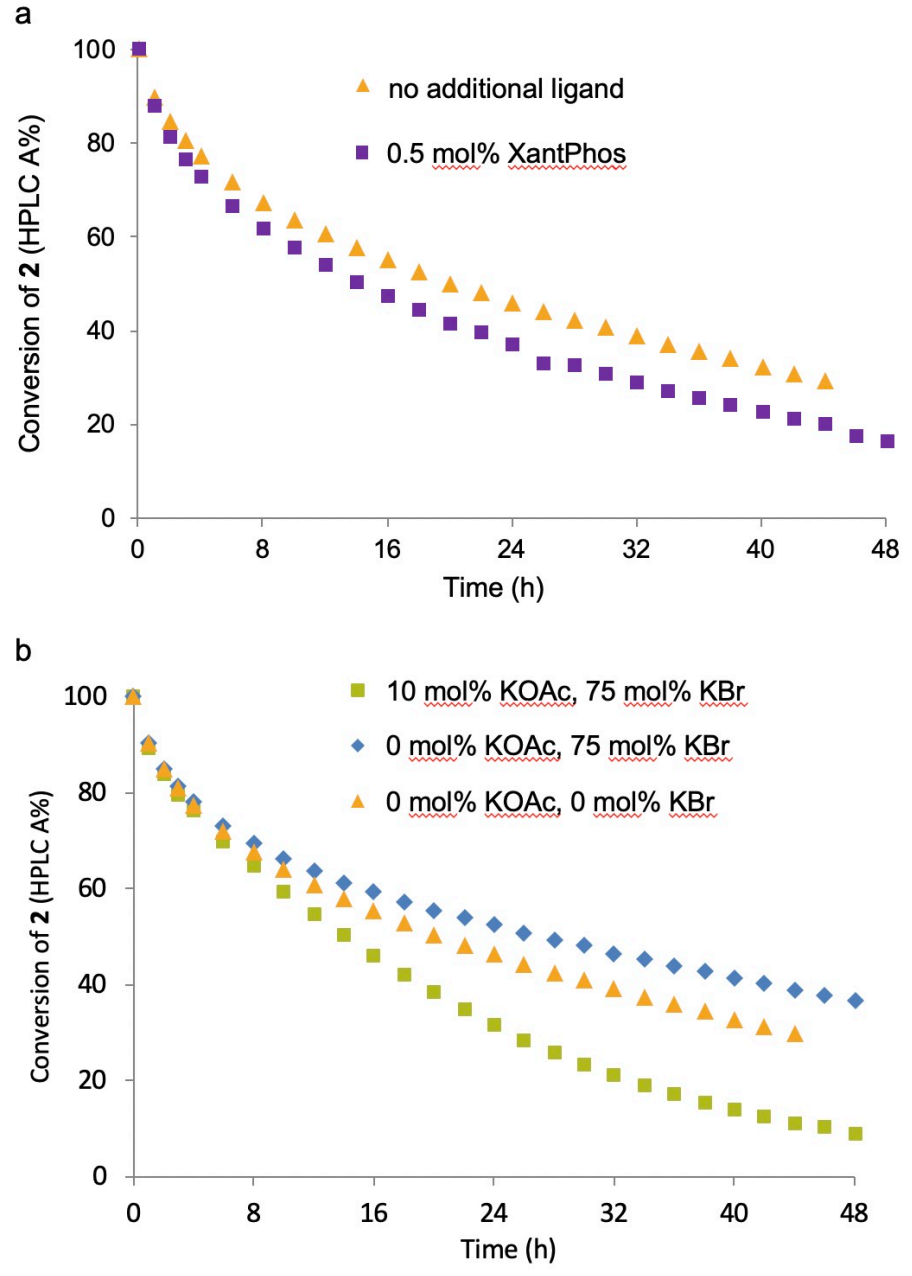